\title{
Thenar Flap in The Index Pulp Loss Cover: A Case Report
}

\section{Soufiane Aharram* | Yahyaoui Mounir | Omar Agoumi | Abdelkarim Daoudi}

*Correspondence: Soufiane Aharram

Address: Service de Traumatologie-Orthopédie, Faculté de Médecine et de Pharmacie d'Oujda, Maroc e-mail $\bowtie$ : aharram.1993@gmail.com

Received: 25 April 2020; Accepted: 04 May 2020

Copyright: (C) 2020 Aharram S. This is an open-access article distributed under the terms of the Creative Commons Attribution License, which permits unrestricted use, distribution, and reproduction in any medium, provided that the original work is properly cited.

\section{ABSTRACT}

We present the case of a young patient admitted for an index pulp injury with loss of substance and exposure of the distal phalanx. A thenar flap was carried out. It has a distinct advantage of low morbidity at the donor site, better texture of the flap. It is a fairly common technique and gives good results.

Keywords: Thenar Flap, Pulp, Index Finger

\section{Introduction}

Several recovery techniques have been described, whether local or regional, to cover the defect of the soft tissue of the fingers. The thenar flap can be used to cover amputations with the fingertips and more extensive loss of the index, middle and thus ring fingers. Also used for nail bed defects. This gives this flap the reliable character with good quality stable skin and excellent cosmetic result.

\section{Case Report}

This is a 31-year-old patient who suffered a domestic accident causing her to severely remove the soft tissue from the tip of the distal phalanx of the index finger of the right hand. Bone and end part of the tendon was exposed, as well as the tip of the phalanx was crushed (Fig. 1,2). A front and side index X-ray did not show any associated bone lesions (Fig. 3).

The patient was admitted to the operating room under the locoregional (axillary) block. First of all: we carried out a careful washing and debridement.

Second step: three small incisions in the thenar compartment, the flap is lifted by slightly oversizing the skin and the subcutaneous fat is incised up to the muscle, taking care to leave deep the nervous elements intended for the thumb (Fig. 4). 


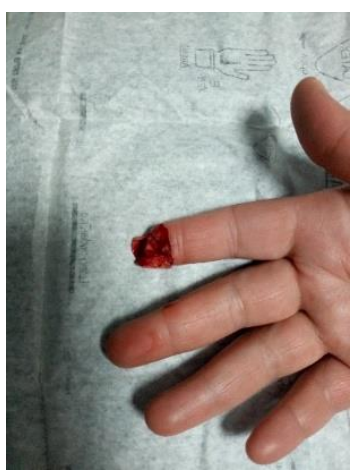

Figure 1: Traumatic disrepair of the index finger.

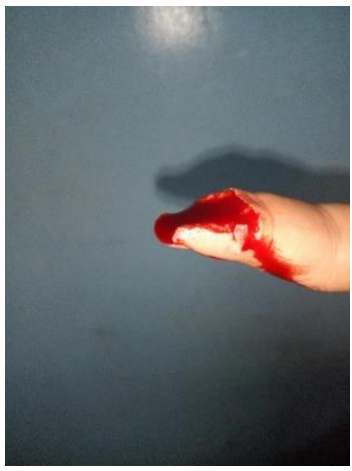

Figure 2: The depth of the trauma on a side view.
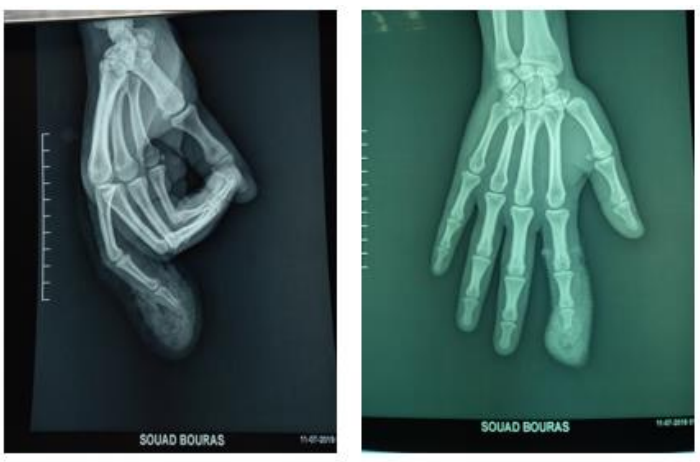

Figure 3: Index x-ray showing no bone lesions.

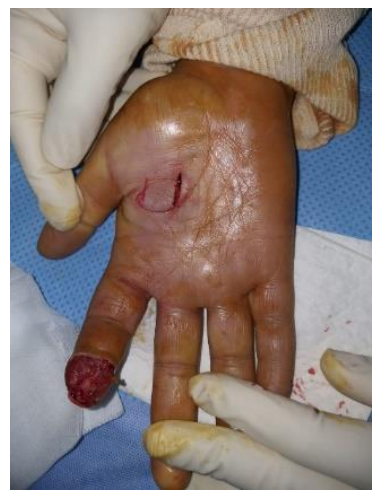

Figure 4: Second step of the lambeau thenar. 
By flexing the finger concerned and bringing it in front of the thenar eminence. The edges of the skin palette are carefully sutured on those of the loss of substance to be covered (Fig. 5). We end the gesture with a bandage in betadiné tulle and a flexible finger restraint system at the donor site without any immobilization.
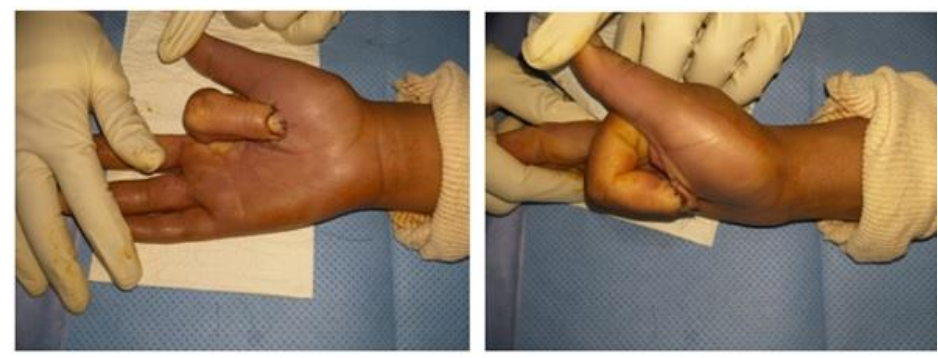

Figure 5: The final appearance of the flap.

Third step: after two weeks of the intervention, a weaning was carried out by section of the hinge as well as a remodeling of the flap on the recipient site (Fig. 6). A total skin graft from the thenar area. Rehabilitation has been started to combat stiffness. After 6 months of the trauma, the patient is satisfied with the flap without feeling uncomfortable (Fig. 7).

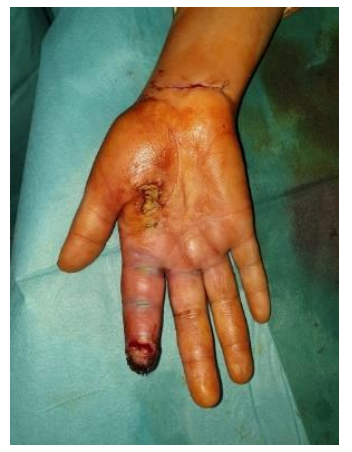

Figure 6: Flap weaning after 2 weeks.

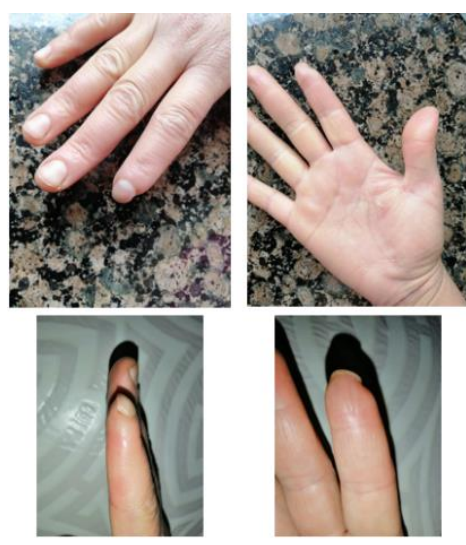

Figure 7: Results after 6 months. 


\section{Discussion}

The first description of this type of flap was made by Gatewood (Gatewood, 1926) in 1926. He described this pedunculated flap to cover a defect on the tip of the index finger. Weaning was performed 12 days after the initial surgery.

Surgeons have also used double thenar flaps to cover several defects with the fingertips and have shown good results (Acar et al., 2014).

The cadaveric studies of Omokawa and colleagues (Omokawa et al., 2001) have shown that the skin of the thenar eminence is richly vascularized by the arterial branches originating from the radial artery. This gives the flap a low rate of morbidity. Also, with a texture that seems to the pulp skin. Donor site scar contracture can be minimized with skin grafting at weaning.

The stiffness of the fingers is manageable by flexion of the metacarpophalangeal joint and extension of the interphalangeal joints during the maintenance phase after surgery of the thenar flap.

To perform appropriate pulp reconstructions, a surgeon must perform a thénar flap 1.5 to $2 \mathrm{~cm}$ long (Lemmon et al., 2008).

\section{Conclusion}

The thenar flap remains a fairly interesting technique with complete survival and excellent functional results.

\section{Conflicts of Interest Statements: None.}

Financial Disclosures: None of the authors has a financial interest in any of the products, devices, or drugs mentioned in this manuscript.

\section{References}

Acar MA, Guzel Y, Gulec A, Turkmen F, Erkocak OF, Yilmaz G. Reconstruction of multiple fingertip injuries with reverse flow homodigital flap. Injury 2014; 45: 1569-73.

Gatewood A. Plastic repair of finger defects without hospitalisation. JAMA 1926; 87: 1479.

Lemmon JA, Janis JE, Rohrich RJ. Soft-tissue injuries of the fingertip: methods of evaluation and treatment: an algorithmic approach. Plast Reconstr Surg 2008; 122: 105e-117e.

Omokawa S, Mizumoto S, Fukui A, Inada Y, Tamai S. Innervated radial thenar flap combined with radial forearm flap transfer for thumb reconstruction. Plast Reconstr Surg 2001; 107: 152-154. 